\title{
PELATIHAN DAN PENDAMPINGAN BAGI DIGITAL PLATFORM "LUAR KULIAH” UNTUK AKSELERASI PELUNCURAN DI PASAR BISNIS
}

\author{
Bayu Sindhu Raharja'), Nia Kurniati Bachtiar2) \\ 1)Program Studi Manajemen Zakat dan Wakaf, Fakultas Syariah, Institut Agama Islam Negeri (IAIN) Surakarta, \\ Surakarta, Jawa Tengah, Indonesia \\ ${ }^{2)}$ Program Studi Manajemen, Fakultas Ekonomi dan Bisnis, Universitas Muhammadiyah Magelang, Magelang, \\ Jawa Tengah, Indonesia \\ corresponding author: Bayu Sindhu Raharja \\ email: bayusindhu@iain-surakarta.ac.id
}

Diterima 07 Februari 2021, Direvisi 03 Maret 2021, Disetujui 08 Maret 2021

\begin{abstract}
ABSTRAK
Saat ini, era disrupsi serta penggunaan internet of things di hampir ada di seluruh kegiatan masyarakat. Oleh karena itu, hal ini menimbulkan efek perubahan atau shifting besar-besaran dalam setiap industri di dunia. Dilain pihak, perusahaan atau badan usaha yang beroperasi secara tradisional pun mulai ditinggalkan baik oleh pemiliknya maupun oleh konsumen. Pemilik usaha kini sangat menyadari bahwa mereka tidak akan mampu bersaing dengan usaha lain yang berbasis teknologi baik dari segi produksi maupun segi pemasaran. Kegiatan pengabdian ini difokuskan pada sebuah kegiatan pendampingan dan pelatihan kepada mitra. Tujuan utamanya adalah membantu rintisan bisnis untuk bisa merealisasikan peluncuran bisnisnya di pasar. Adapun rincian kegiatan pengabdian ini akan dibagi menjadi 3 (tiga) tahap. Tahap pertama, pra start-up activities, kemudian start-up activities, dan yang terakhir adalah sustainability business activities. Mitra utama dari kegiatan pengabdian ini adalah merk rintisan usaha berbasis digital platform dengan merk "Luar Kuliah". Luaran dari kegiatan pengabdian ini adalah terwujudnya merk rintisan usaha "Luar Kuliah" untuk launching di pasar.
\end{abstract}

Kata kunci: start-up; e-commerce; bisnis digital; kewirausahaan; model bisnis

\begin{abstract}
Recently, the disruption era, as well as the use of the internet of things by almost all community activities. Therefore, it affects on the massive changes or shifting in every industry in the world. Conversely, companies or business entities that operate traditionally are starting to be abandoned, both by their owners and by consumers. Today's business owners are well aware that they will not be able to compete with other technology-based businesses both in terms of production and marketing. This service activity is focused on mentoring and training activity for partners. And the main objective of such activity is helping partner to launch the business in current market. The details of this service activity will be divided into 3 (three) stages. The first stage, pre-start-up activities, then startup activities, and the last one is sustainability business activities. The leading partner of this service activity is a digital platform-based business startup brand with the brand "Luar Kuliah". The output of this service activity is the realization of the startup brand "Luar Kuliah" for launching in the market.
\end{abstract}

Keyword: start-up; e-commerce; digital business; entrepreneurship; business model

\section{PENDAHULUAN}

Perkembangan teknologi yang sangat cepat dan penggunaan internet of things di hampir seluruh kegiatan masyarakat, menimbulkan efek perubahan atau shifting besar-besaran dalam setiap industri di dunia. Perubahan ini sangat terlihat di dunia bisnis dimana semua perusahaan mulai dari perusahaan multi nasiona, perusahaan lokal hingga perusahaan kecil tidak hanya menggunakan teknologi sebagai pendukung kegiatannya tapi juga menggantungkan seluruh aktifitas mereka kepada kemajuan teknologi tersebut.
Dilain pihak, perusahaan atau badan usaha yang beroperasi secara tradisional pun mulai ditinggalkan baik oleh pemiliknya maupun oleh konsumen. Pemilik usaha kini sangat menyadari bahwa mereka tidak akan mampu bersaing dengan usaha lain yang berbasis teknologi baik dari segi produksi maupun segi pemasaran. Hal tersebut menjadi alasan yang kuat bagi sebuah usaha berpindah dari usaha konvensional ke usaha yang berbasis teknologi. Dari segi konsumen, usaha yang berbasis teknologi lebih memudahkan mereka dalam mencari, membandingkan dan memesan/membeli produk atau jasa yang 
mereka inginkan. Tentu saja segala kemudahan ini membuat mereka lebih memilih untuk memenuhi kebutuhan mereka melalui medium yang lebih modern. Dengan tingginya demand akan produk atau jasa yang berbasis teknologi, supply terhadap produk dan jasa tersebut pun harus dipastikan mencukupi atau paling tidak sesuai dengan tingginya demand di pasar.

Penjelasan di atas membuat timbulnya kesadaran akan pentingnya kehadiaran usaha berbasis teknologi di sekitar kita. Namun, pengembagan usaha seperti itu tidaklah mudah karena diperlukan sumber daya yang mumpuni. Bukan hanya sumber daya peralatan baik hardware maupun software yang sesuai, namun kualitas dan kapasistas sumber daya manusia lah yang menjadi tonggak utama berdirinya jenis usaha ini karena bukan hanya pengetahuan tentang dunia usaha, manajemen dan keuangan yang diperlukan tapi juga pengetahuan mengenai tata kelola bisnis modern, pemasaran modern hingga strategi menggapai pasar baru yang sesuaikan dengan perkembangan dunia saat ini.

"Luar kuliah" merupakan sebuah rintisan bisnis berbasis digital platform yang dikembangkan oleh mahasiswa - mahasiswa Fakultas Ekonomi dan Bisnis UNIMMA. Secara ide bisnis, rintisan usaha ini sangat menarik, karena berdasarkan analisis five-forces porter usaha ini sangat potensial. Usaha ini sangat segmented, jadi kompetitor di pasar belum terlalu banyak. Akan tetapi, rintisan usaha ini sampai dengan saat ini masih mengalami beberapa kendala sehingga peluncurannya sampai dengan saat ini masih tertunda. Adapun masalah tersebut salah satunya adalah masalah rencana tindak lanjut setelah proses ide rintisan bisnis tersebut dihasilkan. Maka dari itu, kegiatan pengabdian ini bertujuan untuk membantu rintisan usaha tersebut segera meluncur ke pasar.

Mitra dari kegiatan pengabdian ini adalah usaha start-up yang bernama "Luar Kuliah". Kebetulan unit usaha ini dimiliki oleh beberapa mahasiswa Fakultas Ekonomi dan Bisnis UNIMMA. Usaha ini masih masuk dalam kategori usaha rintisan, adapun cakupan usaha ini antara lain:

1. Menyelenggarakan seminar secara online (webinar) sesuai dengan minat dan passion konsumennya

2. Menyelenggarakan kelas offline berupa pelatihan untuk minat usaha tertentu untuk mempersiapkan target pasar mereka untuk terjun ke duania usaha. Contoh: pelatihan sablon, pelatihan desain dll
3. Membangun komunitas berbasis skill sehingga dapat mempersiapkan SDMSDM yang kompeten

4. Menginisiasi kuliah online dengan materi spesifik sesuai dengan kebutuhan pasar modern

Akan tetapi, seiring berjalannya waktu, rintasan usaha mengalami beberapa kendala untuk melakukan launching. Adapun kendala kendala tersebut antara lain:

1. Kurangnya pengetahuan mengenai bisnis rintisan membuat tidak adanya alur proses bisnis yang teratur dan runtun dalam bisnis mereka.

2. Masih lemahnya kemampuan para pemilik usaha untuk melakukan riset pasar, sehingga proses segmentasi, pentargetan, dan pemosisian produknya belum jelas.

3. Kurangnya dana dalam mebangun website dan aplikasi sebagai sarana utama berjalannya bisnis mereka.

Kegiatan pengabdian ini bertujuan untuk melatih, dan mendampingi mitra usaha untuk dapat meluncurkan rintisan bisnisnya tersebut ke pasar.

\section{METODE}

\section{Waktu dan lokasi pelaksanaan kegiatan pengabdian}

Sesuai dengan rancangan kegiatan yang disusun. Kegiatan pengabdian ini dilaksanakan dalam rentang waktu 3 (tiga) bulan, dari bulan Agustus 2020 sampai dengan dengan bulan November 2020. Adapun lokasi kegiatan berada di Kota Magelang.

\section{Mitra Pengabdian}

Mitra kegiatan pengabdian ini adalah startup Luar Kuliah. Unit usaha ini merupakan sebuah rintisan bisnis berbasis digital platform.

\section{Subjek/ Peserta Kegiatan Pengabdian}

Adapun jumlah peserta yang aktif dalam kegiatan pengabdian ini adalah 10 (sepuluh) orang, yang terdiri dari, 1 (satu) CEO (chief executive officer) Luar Kuliah, 1 (satu) COO (chief operation officer) Luar Kuliah, 1 (satu) CFO (chief financial officer) Luar Kuliah, 1 (satu) CMO (chief marketing officer) Luar Kuliah, dan 6 (enam) marketing executive Luar Kuliah.

Kegiatan pengabdian kepada masyarakat ini menggunakan metoda participatory rural appraisal (Ayuniyyah, Pramanik, Saad, \& Ariffin, 2018). Metode ini dipilih karena pertimbangan kefektifannya dalam proses aplikasinya pada beberapa contoh kegiatankegiatan yang lalu (Bar-On \& Prinsen, 1999; Chambers, 1994; Chandra, 2010; 
Narayanasamy, 2009). Mengacu pada Chaiviberst (1994), tahapan pelaksanaan solusi dikelompokkan menjadi 3 yaitu:

\section{a. Tahap persiapan}

Tahap persiapan meliputi:

1) Memberitahukan kegiatan yang akan dilaksanakan kepada pimpinan Fakultas Ekonomi dan Bisnis, karena merk "Luar Kuliah" ini notabene adalah sebuah merk yang digarap dan dikerjakan oleh para mahasiswa - mahasiswa FEB.

2) Menyiapkan teknologi yang akan diterapkan kepada mitra yaitu pembuatan website berikut website designnya, dan platform digital android.

3) Menyusun jadwal kegiatan dan melakukan pembagian tugas anggota tim pelaksana.

\section{b. Tahap pelaksanaan}

Tahap pelaksanaan meliputi:

1) Sosialisasi tentang kegiatan pengabdian pada masyarakat yang akan dilakukan kepada mahasiswa maupun dosen dalam lingkup Fakultas Ekonomi dan Bisnis;

2) Pelatihan yang akan diberikan kepada mitra adalah:

a) Pelatihan tentang kegiatan yang mesti dilakukan saat pre-startup activities, pelatihan ini merupakan sebuah pelatihan yang bertujuan untuk membentuk kesadaran dan kemampuan para mitra tentang kegiatan apa saja yang mesti dikuasai sebelum membentuk startup (Atherton, 2007). Walapun rintisan bisnis "Luar Kuliah" ini telah terbentuk, namun ada beberapa proses yang selama ini masih terlewatkan oleh para mitra. Kegiatan pelatihan ini meliputi, pelatihan riset pasar, pelatihan melakukan estimasi dan prediksi arus kas, serta pelatihan penggunaan media;

b) Pelatihan start-up activities yang meliputi pelatihan, teknik penjualan dan pemasaran produk, teknik mengukur market share dari produk yang mereka miliki (Lange, Mollov, Pearlmutter, Singh, \& Bygrave, 2007);

c) Pelatihan business sustainability activities yang meliputi, teknik penyusunan portfolio bisnis untuk pengajuan pencairan pendanaan (Hopp \& Sonderegger, 2015; Johansen, 2013).

\section{c. Pendampingan}

Pendampingan dilakukan hingga kegiatan pengabdian ini berlangsung selama 4 (delapan) bulan. Kegiatan pendampingan yang akan dilakukan adalah pengoperasian platform digital "Luar Kuliah" berikut strategi bisnis yang dijalankan.

\section{HASIL DAN PEMBAHASAN}

Kegiatan pengabdian ini diawali dengan sosialisasi kegiatan pengabdian. Karena mitra pengabdian adalah mahasiswa FEB Universitas Muhammadiyah Magelang (UNIMMA), maka, sosialisasi dilakukan di lingkungan FEB UNIMMA. Hal ini bertujuan untuk mengkomunikasikan kegiatan pengabdian agar dalam setiap proses dan tahapan kegiatan yang telah direncanakan dapat berjalan lancar. Setelah kegiatan tersebut, mitra akan diberi pelatihan terkait dengan metoda pelaksanaan survei pasar. Setelah diberi pelatihan tersebut, mitra langsung didampingi untuk melakukan kegiatan uji potensi respon pasar. Materi ini, pelatihan serta praktik survei pasar menjadi sangat penting, karena melalui ini potensi bisnis Luar Kuliah dalam jangka panjang akan bisa di estimasi. Selain hal tersebut, uji potensi pasar juga bertujuan untuk mengumpulkan feedback dari calon konsumen potensial untuk pengembangan ide dimensi bisnis yang sudah ada. Sebelum pada akhirnya nanti, bisnis Luar Kuliah benar - benar di jalankan.

Mengacu pada Mooi \& Sarstedt (2011), sebelum melakukan uji potensi pasar, tim pengabdian beserta mitra berdiskusi untuk merumuskan instrumen - instrumen pengukuran pasar yang relevan/sesuai dengan karakteristik/model bisnis "Luar Kuliah”. Adapun pengukuran instrumen uji pasar sebagai berikut: (untuk lebih lengkapnya bisa di akses di laman:

https://docs.google.com/forms/d/1t5a2eGbYd2 wy9Z8XQMg1c0gm48X1ySvKiQIZEcx RHw/e dit?ts=5ca6cc01). Sedangkan hasil dari pengukuran pada setiap instrumen pengukuran survei pasar tersebut sebagai berikut:

\section{Pengukuran intensi calon konsumen;}

1. Apa keinginan Anda setelah lulus dari SMK/SMA/ kuliah/ keinginan lain saat anda sudah bekerja?

90 tanggapan
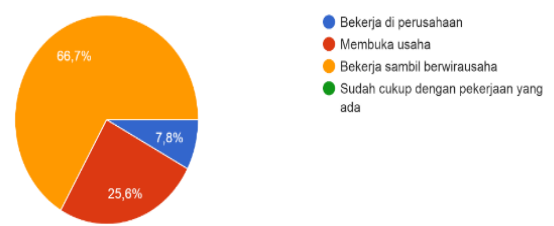

Gambar 1. Intensi Konsumen 
Berdasarkan Gambar 1 di atas, survei pasar yang telah di lakukan menemukan bahwa $66,7 \%$ responden menyatakan bahwa mereka ingin bekerja sambil berwirausaha, $25,6 \%$ fokus berwirausaha, sedangkan sisanya memilih bekerja sebagai pegawai di perusahaan. Fakta ini memberikan ilustrasi positif bagi prospek bisnis Luar Kuliah karena ada sekitar 91,3\% calon konsumen menunjukkan minat berwirausaha. Sebagai bisnis yang berkonsentrasi pada aspek pengembangan non-akademik, $91,3 \%$ calon konsumen ini bisa menjadi konsumen potensial karena Luar Kuliah dapat memberikan pelatihan kepada mereka. Sehingga mereka (para konsumen potensial) dapat mengembangkan bisnis sesuai passion yang mereka tekuni.

\section{Pengukuran keresahan calon konsumen (consumer coriousity);}

\section{Apa yang menjadi ketakutan setelah lulus dari SMK/SMA/kuliah / ketakutan lain saat anda sudah bekerja? 90 tanggapan
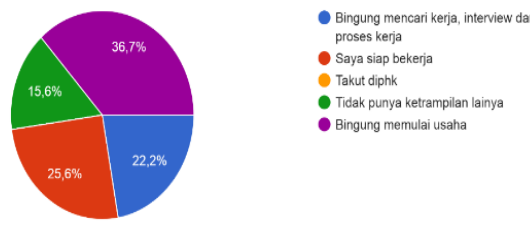

Gambar 2. Keresahan Konsumen

Berdasarkan Gambar 2 di atas, survei pasar yang telah di lakukan menemukan bahwa hanya $25,6 \%$ responden menyatakan bahwa mereka siyap untuk bekerja. Dengan kata lain, ada $74,4 \%$ responden mengalami perasaan yang tidak yakin (resah) setelah mereka menyelesaikan studi. Dan secara spesifik ada $42,3 \%$ responden yang resah tentang apa bakat dan ketrampilan serta bagaimana teknik memulai usaha. Fakta ini memberikan ilustrasi tentang apa konten bisnis potensial yang bisa dikembangkan oleh Luar Kuliah. Sebagai bisnis yang berkonsentrasi pada aspek pengembangan non-akademik, $42,3 \%$ responden tadi bisa menjadi konsumen potensial karena Luar Kuliah dapat menyediakan pelatihan terkait keresahan mereka. Sehingga mereka (para konsumen potensial) dapat menemukan dan ataupun mengembangkan bisnis sesuai passion yang mereka sukai.

\section{Pengukuran kesiapan konsumen;}

3. Apa Anda sudah berpikir untuk mempersiapkan bekal setelah lulus dari SMK/SMA/kuliah / persiapan lain saat anda sudah bekerja?
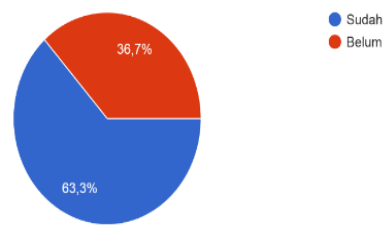

Gambar 3. Kesiapan Konsumen

Berdasarkan Gambar 3 di atas, survei pasar yang telah di lakukan menemukan bahwa hanya $36,7 \%$ responden menyatakan belum siyap untuk mempersiapkan masuk dalam dunia kerja. Sebagai bisnis yang berkonsentrasi pada aspek pengembangan non-akademik, $36,7 \%$ responden tadi bisa menjadi konsumen potensial karena Luar Kuliah dapat memberikan pelatihan kepada $36,7 \%$ responden yang belum siyap menghadapi dunia kerja. Sehingga mereka (para konsumen potensial) dapat menemukan dan ataupun mengembangkan bisnis sesuai passion yang mereka sukai.

4. Pengukuran kesepakatan konsumen tentang suatu konsep;

4. Passion bisa diartikan sebuah perasaan atau emosi terhadap suatu hal yang membuat seseorang sangat beran...isenangi(passion) yang Anda miliki? 90 tanggapan
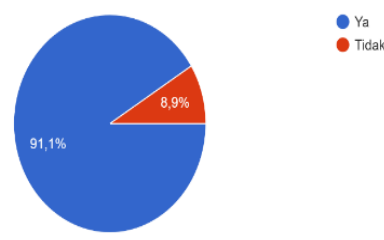

Gambar 4. Kesepakatan Konsumen

Berdasarkan Gambar 4 di atas, survei pasar yang telah di lakukan menemukan bahwa $91,1 \%$ responden menyatakan sepakat bahwa pengembangan karir sesuai dengan passion. Fakta ini memberikan ilustrasi tentang apa konten bisnis potensial yang bisa dikembangkan oleh Luar Kuliah. Sebagai bisnis yang berkonsentrasi pada aspek pengembangan non-akademik, model bisnis ini yang dimiliki oleh Luar Kuliah saat ini sudah tepat. Sehingga mereka $(91,1 \%$ responden) dapat menjadi konsumen potensial bagi Luar Kuliah. 
5. Pengukuran keinginan konsumen (consumer wants);

6. Apakah ada keinginan untuk mengembangkan hal yang Anda senangi (passsion)?
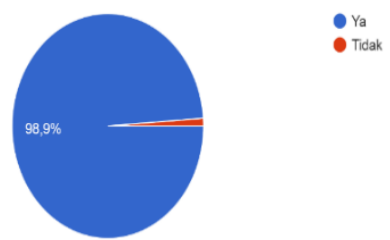

Gambar 5. Keinginan Konsumen

Berdasarkan Gambar 5 di atas, survei pasar yang telah di lakukan menemukan bahwa $98,9 \%$ responden menyatakan bahwa mereka siyap mengembangkan potensi diri mereka sesuai dengan passion yang dimiliki. Fakta ini memberikan ilustrasi positif tentang prospek bisnis Luar Kuliah. Bahwa segmen pasar yang direncanakan dalam model bisnis Luar Kuliah memang benar-benar ada.

6. Pengukuran kebutuhan konsumen (consumer needs);

7. Apakah program pengembangan skill merupakan program yang menarik bagi Anda?

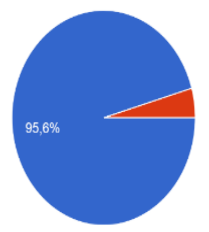

$$
\text { Ya }
$$

Gambar 6. Kebutuhan Konsumen

Berdasarkan Gambar 6 di atas, survei pasar yang telah di lakukan menemukan bahwa hanya $95,6 \%$ responden menyatakan bahwa pengembangan skill merupakan program yang menarik bagi mereka. Fakta ini memberikan ilustrasi positif tentang prospek bisnis Luar Kuliah. Karena responden yang ada tidak hanya sekedar menunjukkan minat. Lebih dari itu, mereka sangat tertarik terhadap program pengembangan skill.
7. Pengukuran pengalaman konsumen (consumer past experiences);

8. Apakah Anda pernah mengikuti program pengembangan skill? 90 tanggapan
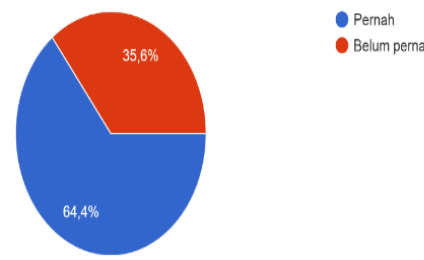

\section{Gambar 7. Pengalaman Konsumen}

Berdasarkan Gambar 7 di atas, survei pasar yang telah di lakukan menemukan bahwa $64,4 \%$ responden menyatakan belum pernah ikut dalam program pengembangan kemampuan/ ketrampilan diri. Data statistik ini bisa menjadi rujukan bagi Luar Kuliah tentang siapa konsumen pertama yang akan menjadi target potensialnya.

8. Pengukuran ketertarikan konsumen (consumer attraction);

\section{Apakah Anda berminat mengikuti program pengembangan skill jika diadakan oleh Perusahaan Start-up? 90 tanggapan

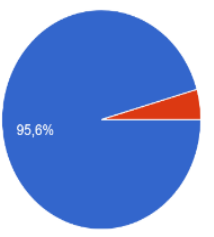 Ya}

Gambar 8. Ketertarikan Konsumen

Berdasarkan Gambar 8 di atas, survei pasar yang telah di lakukan menemukan bahwa hanya $95,6 \%$ responden menyatakan bahwa sangat tertarik untuk ikut bergabung mengikuti program pengembangan kemampuan/ketrampilan diri. Data ini semakin memperkuat bahwa model bisnis Luar Kuliah memang memiliki pasar yang sangat potensial.

Berdasarkan hasil uji pasar yang telah di lakukan, tim pengabdian berani menyimpulkan bahwa kegiatan bisnis Luar Kuliah ini sangat layak untuk dilakukan. Maka langkah selanjutnya yang di lakukan adalah menyiapkan instrumen - instrumen untuk mendukung kegiatan bisnis ini. Karena bisnis Luar Kuliah ini merupakan bisnis yang berbasis media digital, maka instrumen yang paling urgen adalah mengkonstruksi website Luar Kuliah. Adapun 
alamat website dari luar kuliah adalah www.luarkuliah.com.

Disamping menyusun website, kegiatan lain yang diadakan dalam pengabdian ini adalah pelatihan strategi pemasaran. Pelatihan tersebut meliputi beberapa pelatihan dasar tentang strategi segmentasi, menilai dan mengaudit kinerja pasar, strategi konten pemasaran, serta memprediksi pangsar pasar dari sebuah bisnis. Hal ini sangat penting sekali mengingat merk Luar Kuliah ini merupakan sebuah rintisan bisnis. Jadi di perlukan strategi - strategi pemasaran yang efektif untuk meningkatkan awareness dari calon konsumen.

Setelah kegiatan strategi pemasaran di lakukan, langkah selanjutnya adalah launching rintisan bisnis Luar Kuliah. Kegiatan peluncuran merk rintisan bisnis ini dilakukan pada hari Ahad, 03 Maret 2019 di Lapangan Rindam Kota Magelang. Kegiatan peluncuran tersebut berbarengan dengan kegiatan mingguan di Kota Magelang (CFD). Hal ini memang sengaja di lakukan karena peluncuran merk bisnis ini mencoba memanfaatkan keramaian yang ada. Adapun foto - foto kegiatan peluncuran tersebut dapat dilihat pada Gambar 9 berikut:

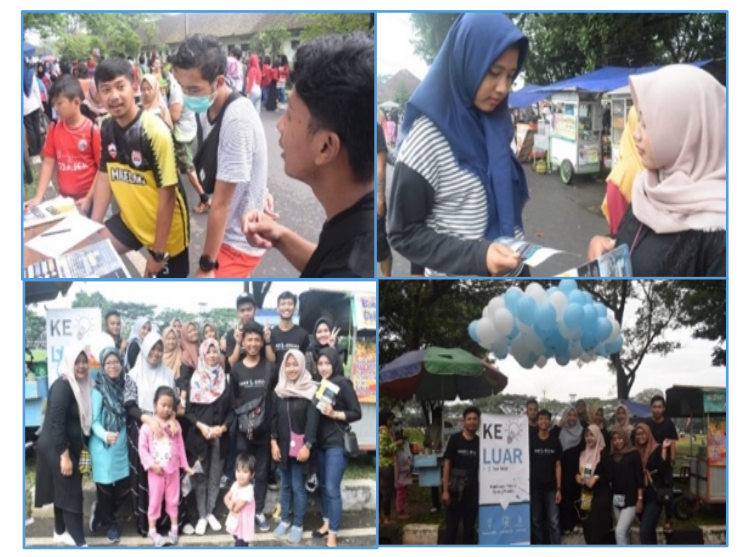

Gambar 9. Peluncuran Bisnis

\section{SIMPULAN}

Kegiatan pengabdian ini merupakan sebuah kegiatan pendampingan terhadap rintisan bisnis berbasis platform digital. Tujuan utama dari kegiatan pengabdian ini adalah mencoba membantu permasalahan mitra, dan mendampingi mitra dalam meluncurkan rintisan bisnisnya. Dan seperti yang telah dijelaskan pada bagian sebelumnya bahwa kegiatan ini didahului dengan kegiatan sosialiasi di lingkungan FEB UNIMMA. Kegiatan sosialisasi berjalan dengan sukses, terutama dari pihak FEB UNIMMA, yang secara penuh mendukung kegiatan ini. Dikarenakan luaran dari kegiatan ini dapat mendukung capaian pembelajaran program studi di bawah naungan FEB UNIMMA.
Melalui kegiatan, baik pelatihan maupun pendampingan. Respon mitra sangat antusias, mengingat dengan kegiatan (pelatihan dan pendampingan) ini konsep yang awalnya baru sebatas ide, bisa diwujudkan/direalisasi menjadi sebuah bisnis yang riil. Sebagai buktinya adalah peluncuran resmi platform digital Luar Kuliah di pasar bisnis (bisa di akses di www.luarkuliah.com). Dampak kegiatan pengabdian ini juga terlihat nyata di acara launching resmi Luar Kuliah di area Lapangan Rindam, Kota Magelang, Jawa Tengah. Antusiasme masyarakat (calon konsumen) sangat ramai. Hal ini salah satunya karena Luar Kuliah tepat melakukan survei pasar dan strategi pemasaran.

Setelah merilis bisnisnya, tahapan pendampingan selanjutnya adalah investor pitching. Namun demikian, kegiatan ini tidak langsung meminta mitra untuk mendekati para investor agar mendapatkan dana. Mereka diminta terlebih dahulu menuangkan konsep yang telah diberikan pada sesi pelatihan dalam bentuk video. Adapun hasil videonya dapat di lihat dalam tautan berikut: https://www.youtube.com/watch?v=1X5jkqjlBd A

Untuk jangka panjang, selain terkait realisasi investor pitching, ada beberapa hal yang mesti diperbaiki kedepannya. Misalnya, platform digital yang bisa diunduh secara bebas di Playstore dan Appstore yang sampai dengan saat ini belum dapat bekerja secara stabil karena masih merupakan web-based application. Selain hal tersebut, kedepan merk rintisan bisnis ini juga membutuhkan konten konten pemasaran yang menarik untuk menarik minat calon konsumen secara efektif.

\section{DAFTAR RUJUKAN}

Atherton, A. (2007). Preparing for business start-up:"pre-start" activities in the new venture creation dynamic. Journal of Small Business and enterprise development.

Ayuniyyah, Q., Pramanik, A. H., Saad, N. M., \& Ariffin, M. I. (2018). Zakat for poverty alleviation and income inequality reduction. Journal of Islamic Monetary Economics and Finance, 4(1), 85-100.

Bar-On, A. A., \& Prinsen, G. (1999). Planning, communities and empowerment: An introduction to participatory rural appraisal. International Social Work, 42(3), 277-294.

Chaiviberst, R. (1994). The origins and Practide of Participatory Rural Appraisal. World Development, 22(7), 953-969. https://www.sciencedirect.com/science larticle/pii/0305750X94901414 
Chambers, R. (1994). The origins and practice of participatory rural appraisal. World development, 22(7), 953-969.

Chandra, G. (2010). Participatory rural appraisal. Katiha, PK, Vaas, KK, Sharma, AP, Bhaumik, U. \& Chandra Ganesh (Eds). Issues and tools for social science research in inland fisheries. Central Inland Fisheries Research Institute, Barrackpore, Kolkata, India. Bulletin(163), 286-302.

Hopp, C., \& Sonderegger, R. (2015). Understanding the dynamics of nascent entrepreneurship_-prestart-up experience, intentions, and entrepreneurial success. Journal of Small Business Management, 53(4), 1076-1096.

Johansen, V. (2013). Entrepreneurship education and start-up activity: a gender perspective. International Journal of Gender and Entrepreneurship.

Lange, J. E., Mollov, A., Pearlmutter, M., Singh, S., \& Bygrave, W. D. (2007). Pre-startup formal business plans and poststart-up performance: A study of 116 new ventures. Venture Capital, 9(4), 237-256.

Mooi, E., \& Sarstedt, M. (2011). A Concise Guide to Market Research. In A Concise Guide to Market Research. https://doi.org/10.1007/978-3-642-

Narayanasamy, N. (2009). Participatory rural appraisal: Principles, methods and application: SAGE Publications India. 